\title{
Emotional Perception of Urban Environments ${ }^{*}$
}

\author{
Graciela Tonello \\ Universidad Nacional de Tucumán, Tucumán, Argentina
}

\author{
Pablo Bobatto \\ Universidad Nacional de Córdoba, Córdoba, Argentina
}

\begin{abstract}
In the frame of a study aiming at identifying the potential of emotion as the affective component of perception, a questionnaire was developed for assessing the involvement of this dimension in the perception of urban environments. The questionnaire was tested in field studies carried out in two cities. It was hypothesized that the street lighting might be the main feature among the overall environmental stimulation of the urban environment, and this may have an impact on emotional perception. The general appraisal of the urban scene was also considered as background predictor.
\end{abstract}

Keywords: emotional perception, questionnaire, street lighting, urban environments

\section{Introduction}

Environmental perception includes cognitive, affective, interpretive, and evaluative components. As opposed to sensation, the term perception is applied to the more complicated processing of complex, often meaningful stimuli like those encountered in everyday life (Bell, Greene, Fisher, \& Baum, 2001). At the same time, the core feature that distinguishes moods from emotions is that moods, in contrast to emotions, are diffuse and global, being moods temporary dispositions to have or to generate particular kinds of emotion-relevant appraisals (Siemer, 2009).

From a neurobiological point of view, emotion involves the entire nervous system, being the limbic and the autonomic nervous systems, especially significant (Dalgleish, Dunn, \& Mobbs, 2009). But it is extremely difficult to find a case of pure emotion because in any normal situation, emotion is affected by appraisal. However, in some contexts, emotion can be seen as prior to cognitions (Franks, 2010).

Appraisal theory claims that emotions are elicited by evaluations (appraisals) of events and situations. The more controversial issues that appraisal theory must continue to confront and address, are the relative importance of appraisal vs. other factors in eliciting emotions. Three processes were suggested by appraisal theories as important for emotion perception: (1) the identification of the emotional significance of a stimulus; (2) the production of an affective state in response to 1; and (3) the regulation of the affective state (Phillips, Drevets, Rauch, \& Lane, 2003).

According to Küller (1991), an emotion is not a state, but a process that evolves in stages, and proceeds in four steps corresponding to the neurophysiological events of arousal/activation, attention/orientation, reward/aversion (or evaluation), and coping/control. This so-called "basic emotional process", will be repeated over and over again, as a response to changes in the human-environment relation. Although some basic

\footnotetext{
*Acknowledgements: The study was supported by the Research Council of the University of Tucumán (CIUNT 26E/425-2). The authors gratefully acknowledge the co-operation of all participants in Córdoba and Tucumán.

Graciela Tonello, Ph.D., Departamento de Luminotecnia, Luz y Visión, Universidad Nacional de Tucumán.

Pablo Bobatto, E.E., Facultad de Ingeniería, Universidad Nacional de Córdoba.
} 
emotional processes may take only seconds to complete, others may last for hours, days, or even years. The most human emotions constitute complex combinations of such basic dimensions, and they should be interpreted in a cognitive and contextual framework.

Environmental psychology has generally taken a dimensional approach to the study of emotions, considering human responses to environmental exposure through a holistic process (Laike, 2009).

Environmental stimuli such as light, noise, heat, air pollution, and crowding provoke greater stress when the individual is unable to cope with them. Real or perceived control over a stressor often causes fewer negative consequences than exposure to stressors that are uncontrollable. In addition, studies considered the possibility that environmental factors could trigger or increase stress symptoms in vulnerable persons (Tonello, 2008).

The luminous environment, specifically light considered as an emotional stimulus, might link together the neurobiological, the appraisal and the environmental approaches (Moruzzi \& Magoun, 1949; Goldstein, 1996).

Antecedents about how street lighting affects people in an emotional broad sense are scarce, except in the case of the spectral power distribution of light sources on safety and visual perception.

Public lighting improves visibility and provides orientation. It also contributes to the perception of comfort and safety of people outside after dark. At present, high pressure sodium lamps are widely used in street lighting. This is in part due to their high efficacy and relatively long lifetime ( $\geq 16,000$ hours). Their use, however, comes at the expense of good colour rendering. Recently developed ceramic metal halide lamps provide many of the advantages of high pressure sodium light sources, in addition to white light and better rendering of colours (Knight, 2010).

MH (metal halide) lighting systems are gaining in acceptance relative to HPS (high-pressure sodium) lighting systems for many night time applications. HPS and MH installations were compared in terms of perceptions of brightness and safety, acceptability for social interaction, facial recognition and eyewitness identification. At equal photopic light levels, a street scene illuminated at night by an MH lighting system was reliably seen as brighter and safer than the same scene illuminated by an HPS system. In terms of acceptability for social interaction, facial recognition and many aspects of eyewitness identification, the measured differences between lighting systems were not as clear (Rea, Bullough, \& Akashi, 2009). Further work is needed to determine how recognition of the identity and intent of other pedestrians is affected by lamp spectrum (Fotios, 2013).

\section{Problem, Objective, and Hypotheses}

Urban users are exposed to a variety of environmental stimuli that are beyond their control, influencing their behavior and moods. Among them, light plays an important role by affecting fundamental aspects of life such as health, welfare and safety.

By means of two field studies, this research work aims to investigate the sensitivity of a subjective method developed to assess the emotional dimension of the urban environment perception in general, and particularly to identify whether street lighting has any influence on the emotional perception of urban users.

The typical bias of field studies that this work show can be overcome by means of its replication in experimental settings.

It was hypothesized that the perception of street lighting, specifically the spectral power distribution of the lamps, together with other environmental factors such as noise, odors, and pollution, and a general appraisal of the environment would have an impact on users' emotions. 


\section{Method}

\section{Sample, Setting, and Measurements}

The study was conducted in the streets of the city centre of two medium sized Argentinean cities of 700,000 and 1,300,000 inhabitants, respectively. The four streets included in this study are considered equal in terms of importance and progress.

The sample was made up of 170 observers for the two cities. All the participants received oral and written instructions as well as information about the project as an investigation of people's perception of public lighting. Table 1 summarizes the characteristics of the two groups of observers.

Table 1

Description of the Participants in the Two Cities and Streets

\begin{tabular}{llc}
\hline & City 1 & City 2 \\
\hline$N$ & 70 & 100 \\
Metal Halide Street & 30 & 50 \\
High Pressure Sodium Street & 40 & 50 \\
Gender: & & \\
Women $(N)$ & 43 & 30 \\
Men $(N)$ & 27 & 20 \\
Range age (years) & $20-68$ & $23-45$ \\
\hline
\end{tabular}

Participation was voluntary for both groups. The data collection took two weeks in both cities. In city 1 the sample was made up of workers belonging to retails along the investigated sidewalks, the questionnaires were delivered on Tuesday at 19:00 hours and collected the next day. In city 2, the sample consisted of pedestrians who filled in the questionnaires in situ. Both groups carried out the evaluations between the time of 20:00 and 22:00 of an unusually warm winter, during half an hour.

Physical measurements (see Table 2) were carried out at approximately the same time as the questionnaires were being filled in.

Table 2

Mean Values of Vertical Illuminance, Noise, Temperature, and Humidity

\begin{tabular}{lllll}
\hline & Illuminance $(\mathrm{lx})$ & Noise $(\mathrm{db})$ & Temperature $\left({ }^{\circ} \mathrm{C}\right)$ & Humidity $(\%)$ \\
\hline MH city 1 & 23 & 80 & 23 & 57 \\
MH city 2 & 55 & 72 & 21 & 66 \\
HPS city 1 & 18 & 80 & 23 & 57 \\
HPS city 2 & 30 & 66 & 21 & 66 \\
\hline
\end{tabular}

The streets were chosen because they were lit by different light sources, namely MH and HPS both lamps of $150 \mathrm{~W}$ in city 1 , and $150 \mathrm{~W}$ and $70 \mathrm{~W}$ respectively in city 2 . Figure 1 shows the spectral power distribution of metal halide (a) and high pressure sodium lamps (b), not measured on the field but from laboratory measurements of the light source.

Figures 2 and 3 show the four streets.

In city 1 , the examined sidewalk belonging to the $\mathrm{MH}$ street lighting has a width of 3.80 meters, with a distance between the 6 meters high lamp-posts of approx. 20 meters.

The HPS lighting consists of one row of 7 meters high lamp-posts, placed every 26 meters along a narrow sidewalk of 2 meters. 
In city 2, the MH lighting consists on high 4 meters posts placed every 15 meters across an area of 8 meters. On the other hand, the sidewalk of the streets lit by HPS lamps has a width of 11 meters, and since it corresponds to the pedestrian street of the city, the lamp-posts are placed into rounded stonemasons every 6 meters along the central line of the street. The height of the post is 4.5 meters and each one has four projectors tilted $45^{\circ}$.

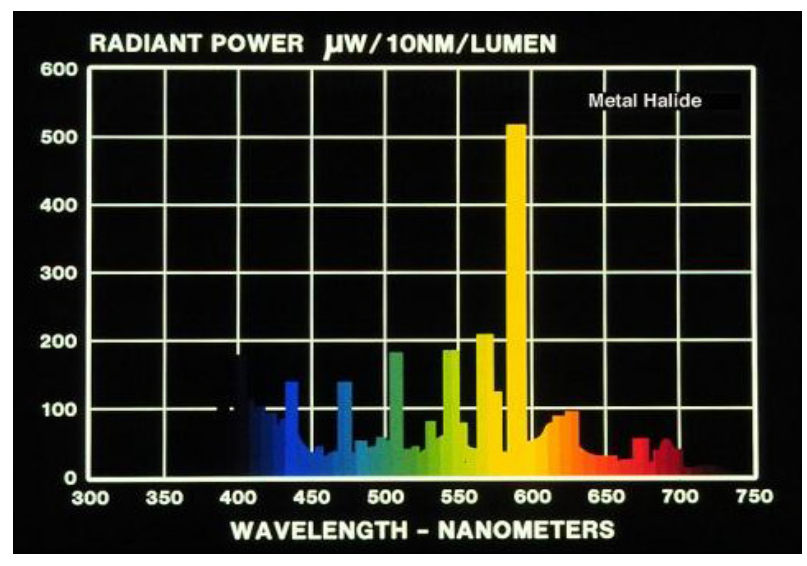

(a)

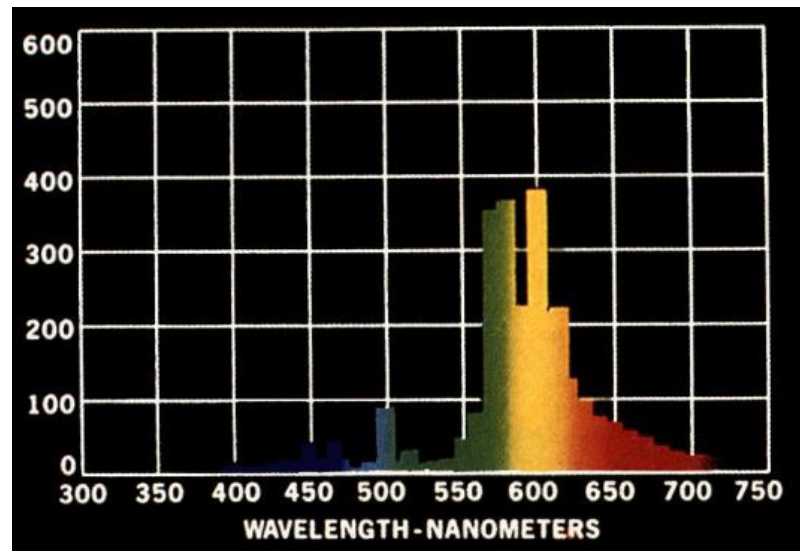

(b)

Figure 1. Spectral power distribution of metal halide (a) and high pressure sodium light sources (b).

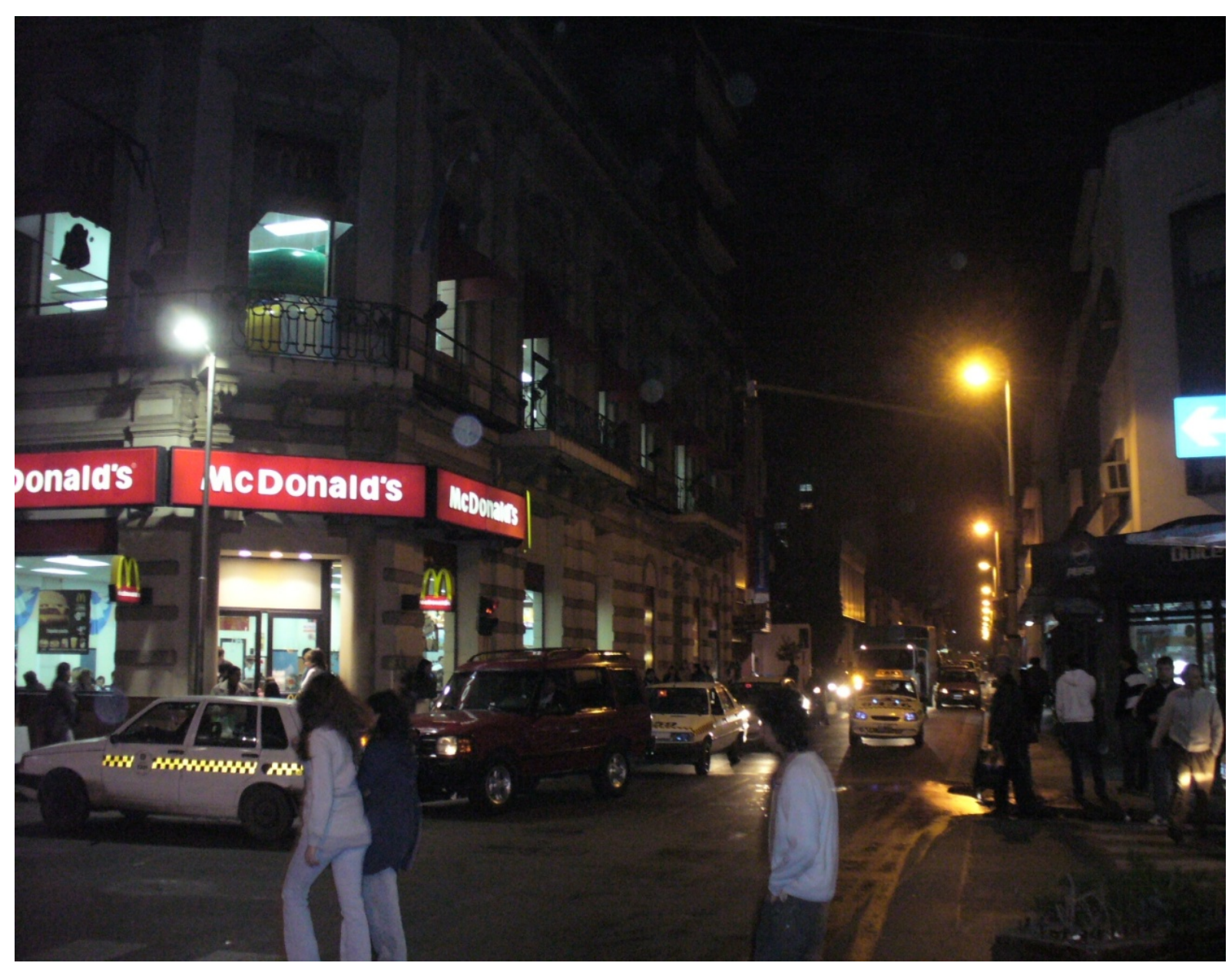

Figure 2. Intersection of the two streets in city 1. 

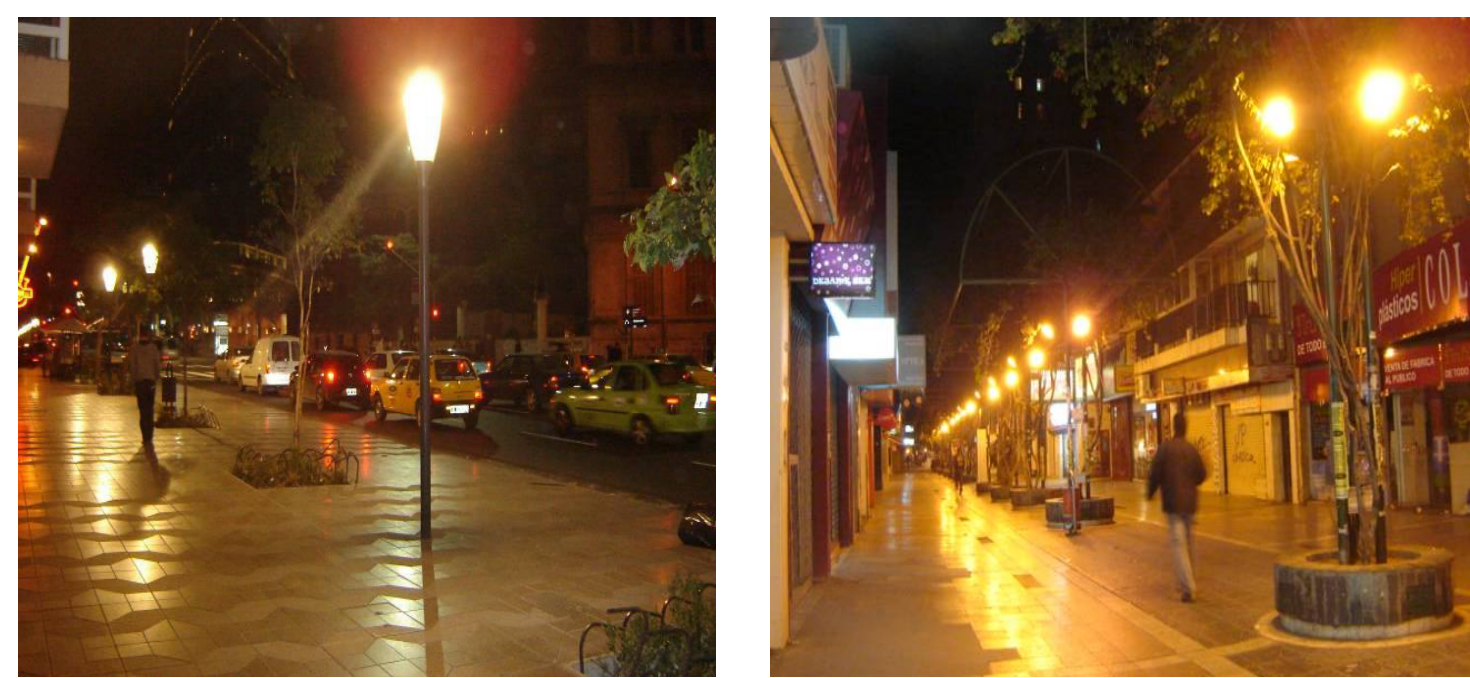

Figure 3. MH and HPS streets in city 2.

The lighting conditions on the four streets are described by averaging the vertical illuminance values measured to the four longitudinal and transverse directions on the sidewalk, at 1.50 meters, under and between the posts.

Lighting levels were according to the Argentinean norm IRAM AADL J2022-2.

As to perceptual measurements, the participants were asked to evaluate the street environment by means of a questionnaire specially developed to this purpose, which was divided into three sections:

The "general appraisal" was assessed on a three-grade scale ranging from "Not at all" to "Totally", by the question: "Do the following adjectives coincide with your appraisal of this street? You can add more adjectives".

The scales to assess "environmental factors" were developed in the Likert style, for example: "I can't maintain a conversation due the noise level". The respondents were asked to tick the appropriate box in a four-grade scale ranging from "Always" to "Never".

The "emotional response" was analysed by means of a list of emotions expressing different reactions that a person might experience while looking at and walking along the street. Its four-grade scale ranged from "Absolutely" to "Not at all".

\section{Data Processing}

First, factor analysis of the emotional perception scales was made in order to confirm the factorial structure of the scales related to the basic emotional process and to explore positive and negative emotional dimensions as well.

One-way ANOVA (analyses of variance) were performed for the three sections of the questionnaire with the spectral power distribution of the lamps as independent variable or factor, in each city.

Also, indices for general appraisal, environmental factors and emotional perception were computed. The internal reliability of the indices was checked by Cronbach's alpha.

Based on theoretical considerations, multiple regression analysis were performed in order to identify the predictive value of environmental factors, general appraisal, spectral distribution of lighting and city, on the emotional perception.

The analyses were carried out in SPSS (Statistical Program for Social Science) 15.0. 


\section{Results}

The factor analysis of the emotional scales resulted in four factors, accounting for $70 \%$ of the total variance (see Table 3 ). The first factor (22\%) loaded high in negative emotions related to the basic emotional dimension of activation, this factor seems to be reinforced by the third factor $(15 \%)$. The second factor $(19 \%)$ represents positive emotions related to the basic emotional dimension of control, and it also seems to be reinforced by the fourth factor $(14 \%)$.

The three sections of the questionnaires, namely general appraisal, environmental factors and emotional perception, as well as the indices computed for each one show high Cronbach's alpha coefficients: 0.94, 0.94, and 0.93 respectively.

An analysis of the significant scales of general appraisal shows, in general, a better evaluation for the streets lit by metal halide lamps (see Tables 4 and 5). In city 1, MH was evaluated in terms of: interesting, modern, stimulating, animated, stressful, pretentious, and repulsive. City 2 as inviting, interesting, luminous, airy, modern, original, spacious, formal, cool, well-kept, timeless, stylish, and expensive.

Table 3

Factor Analysis for the Emotional Perception Scales: Rotated Factor Loadings (Varimax Rotation) Larger Than 0.50 Are Shown

\begin{tabular}{|c|c|c|c|c|}
\hline Scales & Factor 1 & Factor 2 & Factor 3 & Factor 4 \\
\hline Hostility & 0.677 & & & \\
\hline Familiarity & & 0.758 & & \\
\hline Calmness & & 0.676 & & \\
\hline Satisfaction & & 0.792 & & \\
\hline Worry & 0.791 & & & \\
\hline Sadness & & & 0.752 & \\
\hline Friendship & & 0.684 & & \\
\hline Curiosity & & & & 0.788 \\
\hline Energy & & & & 0.698 \\
\hline Boredom & & & 0.781 & \\
\hline Seriousness & & 0.717 & & \\
\hline Loneliness & & & 0.672 & \\
\hline Safety & & & & 0.536 \\
\hline Relaxation & & & & 0.561 \\
\hline Alertness & 0.800 & & & \\
\hline Anxiety & 0.754 & & & \\
\hline Independence & & 0.513 & & \\
\hline Smallness & & & 0.603 & \\
\hline Tension & 0.780 & & & \\
\hline Euphoria & 0.534 & & & \\
\hline Altruism & & 0.700 & & \\
\hline Aggression & 0.702 & & & \\
\hline Total variance & $22 \%$ & $19 \%$ & $15 \%$ & $14 \%$ \\
\hline
\end{tabular}

On the other hand, HPS lighting was rated in city 1 as serious, spacious, modest, and simple, while in city 2 as simple, dynamic, modest, encumbered, and repulsive. 
Table 4

Descriptives of Significant Rating Scales for General Appraisal for the Two Lamps MH and HPS in City 1 (1= "Not at all"; 2 = "Somewhat"; 3 = "Totally")

\begin{tabular}{lllll}
\hline Scales & MH: $M(S D)$ & HPS: $M(S D)$ & $F$ & $p$ \\
\hline Serious & $1.56(0.5)$ & $1.95(0.5)$ & 8.05 & 0.006 \\
Interesting & $2.10(0.6)$ & $1.70(0.6)$ & 7.43 & 0.008 \\
Modern & $2.10(0.7)$ & $1.57(0.6)$ & 9.89 & 0.002 \\
Spacious & $1.30(0.4)$ & $1.70(0.6)$ & 7.55 & 0.008 \\
Stimulating & $1.90(0.8)$ & $1.37(0.6)$ & 9.42 & 0.003 \\
Modest & $1.40(0.4)$ & $1.97(0.6)$ & 15.94 & 0.000 \\
Animated & $2.23(0.6)$ & $1.62(0.7)$ & 14.03 & 0.000 \\
Stressful & $2.43(0.6)$ & $1.87(0.8)$ & 9.14 & 0.004 \\
Pretentious & $1.93(0.6)$ & $1.35(0.6)$ & 13.69 & 0.000 \\
Simple & $1.60(0.4)$ & $2.22(0.7)$ & 15.09 & 0.000 \\
Repulsive & $1.63(0.6)$ & $1.20(0.5)$ & 9.36 & 0.003 \\
\hline
\end{tabular}

Table 5

Descriptives of Significant Rating Scales for General Appraisal for the Two Lamps MH and HPS in City $2(1=$ "Not at all"; 2 = "Somewhat"; 3 = "Totally")

\begin{tabular}{lllll}
\hline Scales & MH: $M(S D)$ & HPS: $M(S D)$ & $F$ & $p$ \\
\hline Inviting & $2.28(0.6)$ & $1.76(0.4)$ & 24.35 & 0.000 \\
Interesting & $2.20(0.6)$ & $1.86(0.5)$ & 10.11 & 0.002 \\
Luminous & $2.32(0.5)$ & $1.92(0.3)$ & 26.92 & 0.000 \\
Airy & $2.46(0.5)$ & $1.92(0.3)$ & 44.37 & 0.000 \\
Modern & $2.40(0.6)$ & $1.70(0.5)$ & 39.36 & 0.000 \\
Original & $2.04(0.4)$ & $1.64(0.6)$ & 13.31 & 0.000 \\
Spacious & $2.36(0.5)$ & $1.96(0.6)$ & 13.31 & 0.000 \\
Formal & $2.12(0.3)$ & $1.62(0.5)$ & 35.90 & 0.000 \\
Simple & $2.04(0.3)$ & $2.32(0.5)$ & 9.23 & 0.003 \\
Cool & $2.40(0.5)$ & $1.78(0.5)$ & 38.31 & 0.000 \\
Dynamic & $1.88(0.6)$ & $2.20(0.6)$ & 7.54 & 0.007 \\
Well kept & $2.64(0.5)$ & $1.88(0.3)$ & 84.23 & 0.000 \\
Modest & $1.60(0.5)$ & $2.04(0.5)$ & 18.29 & 0.000 \\
Encumbered & $1.92(0.5)$ & $2.22(0.6)$ & 7.80 & 0.006 \\
Timeless & $1.96(0.4)$ & $1.58(0.6)$ & 13.55 & 0.000 \\
Stylish & $2.16(0.4)$ & $1.68(0.5)$ & 26.13 & 0.000 \\
Expensive & $2.04(0.5)$ & $1.84(0.5)$ & 11.59 & 0.001 \\
Repulsive & $1.08(0.3)$ & $1.48(0.5)$ & 24.25 & 0.000 \\
\hline
\end{tabular}

In city 1 , the analysis of the significant scales of environmental factors shows a negative evaluation of the street lit by metal halide lamp in terms of unpleasant odors perception and a kind of relief while leaving this street. On the other hand, in city 2 , the same type of light seemed to enhance walking.

In both cities, high pressure sodium lighting gathered negative scores since disorientation and a feeling of hurry were experienced in city 1 . In city 2 , the complaints about environmental factors included the lighting 
level, insecurity, too much luminous advertisements, noise, irritability, bad odors, and feeling of hurry.

More positive emotions for the metal halide lighting were experienced in city 2 (calmness, friendship, curiosity, energy, boredom, safety, relaxation, and altruism) than in city 1 (curiosity, tension, and euphoria).

On the contrary, for the HPS lighting, more positive emotions were experienced in city 1 (calmness, loneliness, and relaxation) than in city 2 (hostility, worry, alertness, anxiety, tension, and aggression).

Table 6

Descriptives of Significant Rating Scales for Environmental Factors for the Two Lamps MH and HPS in City 1 ( 1 = "Always"; 2 = "Sometimes"; 3 = "Rarely"; 4 = "Never")

\begin{tabular}{lllll}
\hline Scales & MH: $M(S D)$ & HPS: $M(S D)$ & \multicolumn{1}{l}{} & $p$ \\
\hline Disorientation & $3.93(0.2)$ & $3.50(0.8)$ & 7.85 & 0.007 \\
Odors & $2.40(0.8)$ & $3.00(0.9)$ & 7.60 & 0.007 \\
Relief while leaving & $2.00(0.9)$ & $2.65(1.0)$ & 7.56 & 0.008 \\
Hurry feeling & $1.73(0.9)$ & $2.87(1.0)$ & 18.93 & 0.000 \\
\hline
\end{tabular}

Multiple regression analysis shows that $74 \%$ of the variance could be explained. The standardized beta-coefficients indicate that the environmental factors overall and the spectral power distribution of lighting within it, were the best predictors of emotional perception experienced by the observers.

Table 7

Descriptives of Significant Rating Scales for Environmental Factors for the Two Lamps MH and HPS in City 2 ( 1 = "Always"; 2 = "Sometimes"; 3 = "Rarely"; 4 = "Never")

\begin{tabular}{lllll}
\hline Scales & MH: $M(S D)$ & HPS: $M(S D)$ & $F$ & $p$ \\
\hline Low lighting level & $3.08(0.9)$ & $2.30(0.8)$ & 20.65 & 0.000 \\
Unsafety & $2.86(0.1)$ & $2.22(0.7)$ & 13.45 & 0.000 \\
Too much advertisements & $3.24(0.1)$ & $2.36(0.1)$ & 17.15 & 0.000 \\
Climate affection & $2.50(0.1)$ & $1.92(0.1)$ & 7.62 & 0.007 \\
Noise and conversation & $2.68(0.1)$ & $1.78(0.1)$ & 21.70 & 0.000 \\
Noise and sickness & $3.52(0.1)$ & $2.68(0.1)$ & 18.13 & 0.000 \\
Irritability & $3.16(0.1)$ & $1.62(0.1)$ & 61.17 & 0.000 \\
Odors & $2.84(0.1)$ & $2.16(0.5)$ & 17.86 & 0.000 \\
Walk & $1.22(0.4)$ & $2.18(0.8)$ & 51.36 & 0.000 \\
Hurry feeling & $2.82(0.8)$ & $2.48(0.1)$ & 72.11 & 0.000 \\
\hline
\end{tabular}

Table 8

Means of Significant Rating Scales for Emotional Perception for the Two Lamps MH and HPS in City $1(1=$ "Total"; 2 = "Moderate"; 3 = "Slight"; 4 = "Null")

\begin{tabular}{lllll}
\hline Scales & MH: $M(S D)$ & HPS: $M(S D)$ & \multicolumn{1}{l}{ F } & $p$ \\
\hline Calmness & $3.60(0.6)$ & $2.85(0.9)$ & 13.57 & 0.000 \\
Curiosity & $2.06(0.9)$ & $2.87(0.9)$ & 11.85 & 0.001 \\
Loneliness & $3.56(0.8)$ & $2.80(1.1)$ & 9.54 & 0.003 \\
Relaxation & $3.73(0.5)$ & $3.05(0.9)$ & 13.03 & 0.001 \\
Tension & $2.10(0.9)$ & $2.82(1.0)$ & 8.94 & 0.004 \\
Euphoria & $2.60(1.0)$ & $3.35(0.9)$ & 9.89 & 0.002 \\
\hline
\end{tabular}


Table 9

Means of Significant Rating Scales for Emotional Perception for the Two Lamps MH and HPS in City $2(1=$ "Total"; 2 = "Moderate"; 3 = "Slight"; 4 = "Null")

\begin{tabular}{lllll}
\hline Scales & MH: $M(S D)$ & HPS: $M(S D)$ & $F$ & $p$ \\
\hline Hostility & $3.26(0.9)$ & $2.70(0.7)$ & 11.28 & 0.001 \\
Calmness & $2.64(0.9)$ & $3.32(0.9)$ & 14.09 & 0.000 \\
Worry & $3.08(0.7)$ & $2.52(0.7)$ & 13.68 & 0.000 \\
Friendship & $2.00(0.8)$ & $2.50(0.7)$ & 10.12 & 0.002 \\
Curiosity & $2.00(0.2)$ & $2.52(0.9)$ & 14.25 & 0.000 \\
Energy & $1.90(0.5)$ & $2.36(1.0)$ & 8.09 & 0.005 \\
Boredom & $2.80(0.7)$ & $3.30(0.9)$ & 8.69 & 0.004 \\
Safety & $1.92(0.6)$ & $2.62(0.5)$ & 30.42 & 0.000 \\
Relaxation & $2.02(0.4)$ & $3.32(0.7)$ & 109.36 & 0.000 \\
Alertness & $3.04(0.7)$ & $2.36(0.6)$ & 22.91 & 0.000 \\
Anxiety & $3.20(0.4)$ & $2.56(0.9)$ & 19.18 & 0.000 \\
Tension & $3.04(0.9)$ & $2.48(0.9)$ & 8.89 & 0.004 \\
Altruism & $2.56(0.8)$ & $3.26(0.7)$ & 18.21 & 0.000 \\
Aggression & $3.68(0.6)$ & $2.92(0.8)$ & 22.62 & 0.000 \\
\hline
\end{tabular}

Table 10

Multiple Regression Analysis for Emotional Index as Dependent on Environmental Factors, General Appraisal, Spectral Power Distribution of Lighting and City

\begin{tabular}{|c|c|c|c|c|c|}
\hline \multirow[b]{2}{*}{ Variables entered } & \multicolumn{5}{|c|}{ Emotional perception } \\
\hline & $B$ & Std. Error & Beta & $t$ & $p$ \\
\hline (Constant) & 0.52 & 0.16 & & 3.29 & 0.001 \\
\hline Environmental factors & 0.65 & 0.04 & 0.79 & 13.90 & 0.000 \\
\hline General appraisal & 0.16 & 0.10 & 0.09 & 1.61 & 0.107 \\
\hline Spectral distribution & 0.21 & 0.04 & 0.19 & 4.72 & 0.000 \\
\hline City & 0.01 & 0.05 & 0.00 & 0.20 & 0.839 \\
\hline
\end{tabular}

Notes. $R=0.86, R^{2}=0.74, R^{2}$ adj $=0.74$, and $p<0.001$.

\section{Discussion}

There is no greater exposure than that of urban users in the sense of the complete lack of control of environmental stimuli that impinge on them. Environmental variables such as lighting and noise may affect people's health in a non-auditive and non-visual way (Hygge, 2002; Küller, Ballal, Laike, Mikellides, \& Tonello, 2006). Nevertheless, many studies on the effects of environmental variables are often carried out on risk communities such as factories or people living close to airports or highways (Evans, 2000).

Beyond vision, light affects people in different ways. Antecedents about how the lit space is captured by observers are well documented and highly inspired by Flynn's protocols (Flynn, Hendrick, Spencer, \& Martyniuk, 1979). As to street lighting, studies about how people are affected in an emotional broad sense are scarce, except for the case of spectral power distribution of light sources and illuminance levels over safety or fear of crime and visual perception (Boyce, Eklund, Hamilton, \& Bruno, 2000; De Kort, 2012; Johansson, Rosén, \& Küller, 2011; Fotios, Cheal, \& Boyce, 2005; Di Laura, Houser, Mistrick, \& Steffy, 2011). 
The main aim of the present paper was to investigate the perception of the urban environment from an emotional approach by means of a questionnaire specially developed for this purpose. Attempts at conceptualizing and measuring emotions have been controversial, but there is a general agreement that in contrast to emotions, moods are considered temporary emotional dispositions-relevant appraisals. Since the most human emotions should be interpreted in a context and environmental psychology has generally taken a dimensional approach to the study of emotions, in this study, the luminous environment linked together the appraisal and the environmental approaches.

Thus, in order to investigate the emotional perception of the selected urban environments, it was assumed that light would be the most important factor in the environmental stimulation pattern, and this was specifically investigated by means of one of the main features of street lighting such as the spectral power distribution of the light sources. Also the general appraisal of the streets was taken into account as predictor.

Because of the fundamental role of emotions as mediators of environmental assessment, they are often confused with environmental descriptors. In this study, the three indices related to general appraisal, environmental factors and emotional perception, each showed a high internal reliability and the results were easy to interpret in relation to the hypotheses. It was shown that environmental conditions affected people's emotional perception, and that lighting had an especially significant impact on the participant's emotional status. General appraisal resulted not relevant as predictor, as well as the city itself.

Generally speaking, metal halide lamps gathered the best evaluations in evaluative terms, while high pressure sodium lighting was rated by means of neutral descriptors.

The exception was the strong adjective "repulsive", which was used in city 1 for MH lighting and in city 2 for HPS. Although this was a field study, the existence of a considerable number of other light sources present on the environments may also have affected the spectral power distribution perceived by the pedestrian.

Environmental factors were perceived in both cities and for the two types of light source, in a high negatively way, especially in city 2 for the HPS light, which corresponds to the pedestrian street of the city, the complaints were stronger.

By means of factor analysis of the emotional scales four factors were obtained, two of them were related to dimensions of the basic emotional process, namely activation and control. The other two factors seemed to reinforce the former by means of positive and negative emotions. Taken together, the streets lit by metal halide were evaluated significantly different in terms of more positive emotions, especially in city 2 than in city 1 . On the contrary, for the HPS lighting, more positive emotions were experienced in city 1 . In line with the environmental outcomes, it seems to be that, again, the status of the street in city 2 (pedestrian) was more relevant than the type of lighting.

Multiple regression analysis showed that environmental factors overall and lighting were the best predictors of the emotional perception experienced by the observers.

Visual properties seems to be more related to affective appraisals (Hanyu, 1997), but the identification of the emotional significance of lighting implies taking into account the whole situation. The greater the separation between light as the stimulus and the desired response, the more likely it is that other factors are operating at the same time across several sensory modalities in the production and regulation of an affective state.

In conclusion, in spite of human emotions influenced by a number of factors and due to difficulties inherent in field studies, the present study was able to show that the strongest impact on emotional perception 
emanated from the environmental conditions and from lighting as part of it.

Finally, it could be concluded that the reliability of the subjective technique developed in this study was fairly satisfactory.

\section{References}

Bell, P. A., Greene, T. C., Fisher, J. D., \& Baum, A. (2001). Environmental psychology (5th ed.). Forth Worth: Harcourt College Publishers.

Boyce, P. R., Eklund, B. J., Hamilton, B. J., \& Bruno, L. D. (2000). Perceptions of safety at night in different lighting conditions. Lighting Research \& Technology, 32, 79-91.

Dalgleish, T., Dunn, B., \& Mobbs, D. (2009). Affective neuroscience: Past, present, and future. Emotion Review, 1(4), $355-368$.

De Kort, Y. (2012). Light distribution in dynamic street lighting: Two experimental studies on its effects on perceived safety, prospect, concealment, and escape. Journal of Environmental Psychology, 32, 342-352.

Di Laura, D. L., Houser, K. W., Mistrick, R. G., \& Steffy, G. R. (2011). The lighting handbook: Reference and application (10th ed.). New York: Illuminating Engineering Society.

Evans, G. W. (2000). Environmental stress and health. In Erlbaum (Ed.), Handbook of health psychology. Mahweh, N. J..

Flynn, J., Hendrick, C., Spencer, T., \& Martyniuk, O. (1979). A guide to methodology procedures for measuring subjective impressions in lighting. Journal of IES, 96-108.

Fotios, S. (2013). Maintaining brightness while saving energy in residential roads. Lighting Research \& Technology, 45(1), 7-21.

Fotios, S., Cheal, C., \& Boyce, P. R. (2005). Light source spectrum, brightness perception and visual performance in pedestrian environments: A review. Lighting Research \& Technology, 271-294.

Franks, D. (2010). Emotions on a continuum. Emotion Review, 2, 105. doi: 10.1177/1754073909355008.

Goldstein, E. B. (1996). Sensation \& perception (4th ed.). Brooks/Cole Publishing Company.

Hanyu, K. (1997). Visual properties and affective appraisals in residential areas after dark. Journal of Environmental Psychology, $17,301-315$.

Hygge, S. (2002). Noise: Effects on health. Cambridge Handbook of Psychology, Health and Medicine.

Johansson, M., Rosén, M., \& Küller, R. (2011). Individual factors influencing the assessment of outdoor lighting of an urban footpath. Lighting Research and Technology, 43, 31-43.

Knight, C. (2010). Field surveys of the effect of lamp spectrum on the perception of safety and comfort at night. Lighting Research \& Technology, 42, 313-329.

Küller, R. (1991). Environmental assessment from a neuropsychological perspective. In T. Gärling, \& G. W. Evans (Eds.), Environment, cognition and action: An integrated approach (pp. 111-147). Oxford: Oxford University Press.

Küller, R., Ballal, S., Laike, T., Mikellides, B., \& Tonello, G. (2006). The impact of light and color on psychological mood: A cross-cultural study of indoor work environments. Ergonomics, 49, 1496-1507.

Laike, T., \& Tonello, G. (2009). Building- and work-related symptoms, a multivariate exploratory study of office environments. Journal of Light \& Visual Environment, 33(3), 147-152.

Moruzzi, G., \& Magoun, H. (1949). Brain stem reticular formation and activation of the EEG. Electroencephalography and Clinical Neurophysiology, 1, 445-473.

Phillips, M., Drevets, W., Rauch, S., \& Lane, R. (2003). Neurobiology of emotion perception I: The neural basis of normal emotion perception. Biol. Psychiatry, 505(54), 504-514.

Rea, M., Bullough, J., \& Akashi, Y. (2009). Several views of metal halide and high-pressure sodium lighting for outdoor applications. Lighting Research \& Technology, 41(4), 297-320.

Siemer, M. (2009). Mood experience: Implications of a dispositional theory of moods. Emotion Review, 1, 256. doi: $10.1177 / 1754073909103594$.

Tonello, G. (2008). Seasonal affective disorder: Lighting research and environmental psychology. Lighting Research \& Technology, 40(2), 103-110. 